\title{
Strontium ranelate and alendronate have differing effects on distal tibia bone microstructure in women with osteoporosis
}

\author{
René Rizzoli • Michel Laroche • Marc-Antoine Krieg • \\ Isolde Frieling $\cdot$ Thierry Thomas $\cdot$ Pierre Delmas • \\ Dieter Felsenberg
}

Received: 7 April 2010 / Accepted: 16 May 2010 / Published online: 29 May 2010

(c) The Author(s) 2010. This article is published with open access at Springerlink.com

\begin{abstract}
The structural basis of the antifracture efficacy of strontium ranelate and alendronate is incompletely understood. We compared the effects of strontium ranelate and alendronate on distal tibia microstructure over 2 years using HR-pQCT. In this pre-planned, interim, intention-totreat analysis at 12 months, 88 osteoporotic postmenopausal women (mean age $63.7 \pm 7.4$ ) were randomized to strontium ranelate $2 \mathrm{~g} /$ day or alendronate $70 \mathrm{mg} /$ week in a double-placebo design. Primary endpoints were changes in microstructure. Secondary endpoints included lumbar and hip areal bone mineral density (aBMD), and bone turnover markers. This trial is registered with http://www. controlled-trials.com, number ISRCTN82719233. Baseline
\end{abstract}

\section{R. Rizzoli ( $($ )}

Division of Bone Diseases,

Department of Rehabilitation and Geriatrics,

Geneva University Hospitals and Faculty of Medicine,

1211 Geneva 14, Switzerland

e-mail: Rene.Rizzoli@unige.ch

M. Laroche

Rangueil Hospital, Toulouse, France

M.-A. Krieg

Department of Muskuloskeletal Medicine,

CHUV, Lausanne, Switzerland

I. Frieling

Osteoporosezentrum, Hamburg, Germany

T. Thomas

INSERM U890, University Hospital, Saint-Etienne, France

P. Delmas

Edouard Herriot Hospital, Lyon, France

D. Felsenberg

Charité Campus Benjamin Franklin, Berlin, Germany characteristics of the two groups were similar. Treatment with strontium ranelate was associated with increases in mean cortical thickness (CTh, 5.3\%), cortical area (4.9\%) and trabecular density $(2.1 \%)$ (all $P<0.001$, except cortical area $P=0.013$ ). No significant changes were observed with alendronate. Between-group differences in favor of strontium ranelate were observed for $\mathrm{CTh}$, cortical area, BV/TV and trabecular density $(P=0.045,0.041,0.048$ and 0.035 , respectively). aBMD increased to a similar extent with strontium ranelate and alendronate at the spine $(5.7 \%$ versus $5.1 \%$, respectively) and total hip (3.3\% versus $2.2 \%$, respectively). No significant changes were observed in remodeling markers with strontium ranelate, while suppression was observed with alendronate. Within the methodological constraints of HR-pQCT through its possible sensitivity to X-ray attenuation of different minerals, strontium ranelate had greater effects than alendronate on distal tibia cortical thickness and trabecular volumetric density.

Keywords Biochemical markers - Bone mineral density · Cortical bone $\cdot$ Microstructure $\cdot$ Trabecular bone

\section{Introduction}

Bone fragility increases as age advances because of the appearance of abnormalities in bone remodeling [1]. The negative balance between the relatively greater volume of bone resorbed by osteoclasts than that subsequently deposited by osteoblasts in the basic multicellular unit (BMU) combined with a high rate of bone remodeling produce trabecular thinning, loss of trabeculae, cortical porosity and cortical thinning [2].

Several agents reduce the risk of fractures in women with postmenopausal osteoporosis [3]. However, the 
microstructural changes that reduce disease progression or partly reverse bone fragility are not completely understood, in part, because non-invasive techniques for measuring them have only recently become available [4-6]. Defining these changes is important because only a small proportion of the fracture risk reduction with antiresorptives is accounted for by the increase in aBMD. Indeed, aBMD does not capture the contribution of the reduction in cortical and trabecular thinning, or intra-cortical porosity that may occur in response to therapy $[2,7]$.

The antiresorptive agent alendronate reduces the rate of remodeling by about $60 \%$ [8]. Following initiation of treatment, steady state is perturbed as many cavities excavated by high remodeling before treatment partly filled by bone formation while $40 \%$ fewer new BMUs in their resorptive phase appear [9]. The result of this perturbation is a net rapid increase in aBMD with alendronate [10]. However, no longitudinal in vivo data in humans are available to determine the microstructural changes that accompany this modification. In cross-sectional studies on single bone biopsies from postmenopausal osteoporotic women, alendronate preserves existing architecture but has not been reported to improve or restore the architectural integrity of bone [11-13]. Bone strength has been shown to increase in monkeys after treatment with alendronate [14].

Strontium ranelate does not reduce the rate of bone remodeling as assessed by dynamic histomorphometry [15]. It does increase in vitro pre-osteoblastic cell replication and osteoblastic differentiation with mineralized nodule formation [16, 17]. Exposure of cells to strontium ranelate in vitro increases the ratio of osteoprotegerin to receptor activator of nuclear factor kappa B ligand (OPG/ RANKL) in the medium, while treatment of cells reduces resorption in calvaria $[18,19]$. However, there is no in vivo evidence for a reduction in volume of bone resorbed by osteoclasts or an increase in mean wall thickness (a measure of the volume of bone formed by the BMU) with strontium ranelate [15]. Nevertheless, $\mu \mathrm{CT}$ analysis on unpaired biopsies from patients treated for 3 years with strontium ranelate suggests a higher cortical thickness and trabecular number than in the placebo group [15]. Results on 4 paired iliac crest bone biopsies from postmenopausal osteoporotic women from a 3-year phase III study suggest that these changes might be due to improvement in trabecular and cortical bone microstructure [15], an observation requiring confirmation in larger-scale studies. There is also evidence for improvements in bone strength with strontium ranelate [20].

The development of non-invasive methods for quantifying bone microstructure has made it possible to study the early changes in bone structure that may, in part, explain fracture risk reductions observed with antiosteoporotic agents $[5,6]$. We compared the effects of strontium ranelate and alendronate, both of which have demonstrated antifracture efficacy [21-23], on bone microstructure of the distal tibia and distal radius using HR-pQCT in a pre-specified interim analysis at 1 year, in a trial lasting 2 years.

\section{Materials and methods}

Study design

In this randomized, double-blind, double-dummy, two-year study, patients were randomly assigned (1:1) to strontium ranelate $2 \mathrm{~g} / \mathrm{day}$ or alendronate $70 \mathrm{mg} /$ week. All received calcium $(500 \mathrm{mg}$ ) and vitamin D (400 IU) supplementation. Compliance was defined as the number of sachets taken divided by the theoretical number of sachets to be taken. Patients were ambulatory Caucasian women, aged $\geq 50$, at least 5 years after menopause with a lumbar, femoral neck, or total hip T-score $\leq-2.5$. The main exclusion criteria were body mass index (BMI) $>30$ or $<18 \mathrm{~kg} / \mathrm{m}^{2}$, diseases and treatments that interfere with bone metabolism (bisphosphonate for more than 1 year, strontium ranelate or glucocorticoids in the previous year, calcitonin within previous 6 months, or hormone replacement therapy within previous 3 months), oesophageal disease, and patients at risk of venous thrombo-embolism. This trial is registered with http://www.controlled-trials.com, number ISRCTN8 2719233. The protocol was approved by local ethics committees and followed ethical principles stated in the Declaration of Helsinki, 1964, amended Edinburgh 2000. All women gave their written informed consent prior to participation.

\section{HR-pQCT techniques}

HR-pQCT (Xtreme CT, Scanco Medical AG, Bruttisellen, Switzerland) examinations were performed at baseline, at 3 and 6 months, and then every 6 months at the non-dominant distal tibia and distal radius. For tibia, the reference line was set at the distal joint limit and for the radius at the most proximal location of the sub-chondral plate. The region of interest (ROI) consisted of 110 slices measured proximally to a $22.5-\mathrm{mm}$ point from the reference line for the tibia and at $9.5 \mathrm{~mm}$ for the radius. Scans were read centrally (Scanco Medical AG). The central facility was blind to treatment assignment. Scan quality was rated as follows: very good quality, exam without any movement artifacts; good quality, minor movement artifacts not affecting the integrity of the cortical circumference; medium quality, clearly visible movement artifacts with horizontal streaks at cortical edge; poor quality, marked movement artifacts with disruption in cortical edge and image partially blurred; and very poor quality, completely blurred images. A scan was 
considered as assessable if it was rated very good or good quality. Daily quality controls were centrally reviewed, and cross-calibration of the devices was performed using a density phantom and an anthropomorphic phantom (a nonhuman bone specimen prepared by $\mathrm{Dr} \mathrm{M}$. A Krieg, Lausanne, Switzerland) to follow the stability of both density and structural parameters.

The methods used to process and validate the HR-pQCT data have been reported elsewhere [5, 6]. In brief, cortical and trabecular compartments were separated by segmentation using a low-pass filter. The threshold to determine cortical bone from trabecular bone was set at $1 / 3$ of the apparent cortical bone density value [24]. Cortical thickness (CTh) was the mean cortical volume divided by the outer bone perimeter. Trabecular bone density (Dtrab, trabecular volumetric BMD) was computed as the average mineral density within the trabecular volume of interest. Trabecular bone volume fraction (BV/TV) was derived from Dtrab $(B V / T V=100 \times$ Dtrab/1200). Trabecular number $(\mathrm{TbN})$ was evaluated using the Ridge number [5]. $\mathrm{TbN}$ was the inverse of mean spacing of the mid-axes. Heterogeneity of the trabecular network (Tb.1/N.SD) was evaluated measuring the SD of the individual distribution of the trabeculae separation. Trabecular thickness (TbTh) and separation (TbSp) derived from BV/TV and $\mathrm{TbN}: \mathrm{TbTh}=$ $(\mathrm{BV} / \mathrm{TV}) / \mathrm{TbN}$ and $\mathrm{TbSp}=(1-\mathrm{BV} / \mathrm{TV}) / \mathrm{TbN}$ [1]. Periosteal perimeter and cross-sectional area (CSAtotal, $\mathrm{mm}^{2}$ ) of the tibia and radius were used to match the volumes of interest on the baseline and follow-up scans. Area of the cortical bone $\left(\mathrm{CSA}_{\text {cort }}\right)$ and the trabecular bone $\left(\mathrm{CSA}_{\text {trab }}\right)$ was calculated. For follow-up, only the bone volume common to all assessable scans was used to assess density and microstructure. Common region was $93.0 \%$ (range, 74-99; median, $94.0 \%$ ).

\section{Other analyses}

Total hip, femoral neck and lumbar aBMD was measured by dual-energy X-ray absorptiometry (DXA) using Hologic or Lunar devices at baseline, at 1 and 2 years. Baseline values are means of two examinations. A cross-calibration program was performed throughout the study (Dr M-A Krieg). Bone markers were assessed at baseline, 3 and 6 months, and then every 6 months over 2 years. The bone formation marker bone alkaline phosphatase (b-ALP), and the bone resorption marker $\mathrm{C}$-telopeptides crosslinks of type-1 collagen (S-CTX) were centrally assessed (Supreme, Liège, Belgium). b-ALP was assayed by immunoradiometric assay $\left(\right.$ Tandem $^{\circledR}$-ROstase ${ }^{\circledR}$, Beckman Coulter, San Diego, CA, USA), and S-CTX was assayed using an enzyme-linked immunosorbent assay (Serum CrossLaps ${ }^{\circledR}$ ELISA, Nordic Bioscience Diagnostic, Herlev, Denmark). Adverse events were recorded at each study visit.
Full blood cell count, creatinine, blood calcium and blood strontium were measured at all visits.

\section{Statistical analysis}

The study was exploratory. No formal sample size calculation was performed. However, a calculation of the study power was conducted and showed that, with a risk $\alpha=0.05$, the statistical power to detect a difference was $86 \%$ for CTh and $70 \%$ for Dtrab. An interim pre-planned analysis was performed at 1 year while maintaining the blinding for the sponsor, investigator and patients. All efficacy analyses were performed in intention-to-treat (ITT) and included randomized patients having taken at least one dose of study medication, with a baseline and postbaseline assessable HR-pQCT scans. All analyses were performed on non-calibrated data. For the tibia, $92 \%$ of the patients had at least two scans rated as good or very good quality. For the radius, $28 \%$ of the examinations were not satisfactory. Criteria analyzed were as follows: $\mathrm{TbN}, \mathrm{Tb} . \mathrm{Th}, \mathrm{TbSp}, \mathrm{CTh}$, Tb.1/N.SD, BV/TV, $\mathrm{D}_{\text {cort }}$ (cortical volumetric BMD), $\mathrm{D}_{\text {trab }}$ (trabecular volumetric $\mathrm{BMD}$ ), $\mathrm{CSA}_{\text {total }}, \mathrm{CSA}_{\text {trab }}$ and $\mathrm{CSA}_{\text {cort }}$.

Relative change from baseline to last observation (end) at the 1-year visit was analyzed with a linear model with center as covariate (fixed effect). The robustness of this main analysis was verified using the same model with center as random effect. Moreover, since the distribution of HR-pQCT data is not well defined, a second robustness analysis was performed using a non-parametric approach without adjustment based on Hodges-Lehmann's estimator. This type of non-parametric approach avoids hypotheses on the normality of the distribution of the data usually made in the parametric model.

Treatment effect was analyzed using a Student $t$ test or a Wilcoxon signed-ranks test, and treatment groups were then compared using Student $t$ test based on the overall general linear model (least-squares norm) or with a MannWhitney Wilcoxon test when appropriate. The withingroup results are presented as means $\pm \mathrm{SD}$ or median when non-normally distributed, and between-group differences are presented as estimates \pm SE. Similar analyses were performed for aBMD and bone turnover markers. Safety was analyzed using descriptive statistics. The type I error rate was set at $5 \%$.

Correlation between cortical thickness and bone strontium content

To evaluate a possible influence of bone strontium content on CTh measurement by computerized tomography, we analyzed the correlation between CTh and bone strontium content in 10 biopsies from postmenopausal women 
treated for 3 years with strontium ranelate $2 \mathrm{~g} /$ day in the SOTI and TROPOS trials $[15,21,22,25]$. In brief, the embedded biopsy blocks were examined at $20 \mu \mathrm{m}$ isotropic resolution using a $\mu$ CT scanner $(\mu \mathrm{CT} 40$, Scanco Medical AG, Bruettisellen, Switzerland). Mineralized bone was separated from bone marrow with a 3D segmentation algorithm. CTh was calculated as the average thickness of the $3 \mathrm{D}$ cortex from the inner to the outer cortical surfaces of the biopsy specimens. For measurement of bone strontium, a part of the embedded bone biopsies was subjected to nitric acid/perchloric acid digestion at high temperature. Total bone calcium and strontium concentrations were measured by inductively coupled plasma optical emission spectrometry using a vacuum polychromator. Total bone strontium content was calculated and expressed as the ratio $\mathrm{Sr} / \mathrm{Sr}+\mathrm{Ca}$. In addition, we analyzed the correlation between distal tibia cortical thickness and area, and serum strontium levels, as a surrogate of bone strontium content, since there were no bone biopsies collected in the present trial.

Role of the funding source

Servier funded this study. Statistical analyses were subcontracted by Servier to Biotrial (Rennes, France). Data concerning HR-pQCT, biochemical markers and blood strontium were collected centrally by independent centers and transferred to Biotrial for statistical analysis. BMD print-outs were sent directly from the investigator centers to Biotrial and data captured. Remaining data collected in this study were held by Servier, locked, and then transferred to Biotrial. Only Biotrial had access to the decoding list. To maintain blinding, results of quantitative data analyses were given by treatment groups (mean $\pm \mathrm{SD}$ ), but minimal and maximal values, and values that could lead to the identification of a patient, were not provided. For qualitative data, only statistics on the whole population were provided. All authors reviewed the manuscript and jointly agreed to submit the final version of the manuscript. The corresponding author had access to all the data and had the final responsibility for the decision to submit the manuscript.

\section{Results}

The two groups had comparable baseline characteristics (Table 1). Of 88 patients randomized, 75 (85\%) completed the first year and 85 (97\%) were included in the ITT population. Compliance was $\geq 80 \%$ in $93 \%$ of subjects. Treatment duration and exposure were similar in the two groups.

For the tibia, at 12 months, $\mathrm{D}_{\text {cort }}$ increased by $1.1 \pm$ $2.7 \%(P=0.005)$ with strontium ranelate but not with
Table 1 Baseline characteristics

\begin{tabular}{|c|c|c|}
\hline & $\begin{array}{l}\text { Strontium } \\
\text { ranelate } \\
(n=44)\end{array}$ & $\begin{array}{l}\text { Alendronate } \\
(n=44)\end{array}$ \\
\hline Number of subjects & 44 & 44 \\
\hline Age (years) & $63.7 \pm 7.3$ & $63.8 \pm 7.6$ \\
\hline Height $(\mathrm{cm})$ & $160 \pm 6$ & $158 \pm 6$ \\
\hline Weight $(\mathrm{kg})$ & $59.3 \pm 9.2$ & $56.5 \pm 7.6$ \\
\hline BMI $\left(\mathrm{kg} / \mathrm{m}^{2}\right)$ & $23.1 \pm 3.3$ & $22.6 \pm 2.7$ \\
\hline L1-L4 BMD (g/cm²) & $0.759 \pm 0.093$ & $0.745 \pm 0.097$ \\
\hline Lumbar T-score & $-2.6 \pm 0.8$ & $-2.7 \pm 0.8$ \\
\hline Femoral neck BMD $\left(\mathrm{g} / \mathrm{cm}^{2}\right)$ & $0.625 \pm 0.110$ & $0.614 \pm 0.103$ \\
\hline Femoral neck T-score & $-1.9 \pm 0.9$ & $-2.0 \pm 0.7$ \\
\hline $\mathrm{D}_{\text {cort }}\left(\mathrm{mg} \mathrm{HA} / \mathrm{cm}^{3}\right)$ & $750.8 \pm 86.8$ & $745.8 \pm 77.9$ \\
\hline $\mathrm{CTh}(\mu \mathrm{m})$ & $723 \pm 240$ & $752 \pm 262$ \\
\hline $\mathrm{BV} / \mathrm{TV}(\%)$ & $94 \pm 25$ & $93 \pm 27$ \\
\hline $\mathrm{D}_{\mathrm{Tb}}\left(\mathrm{mg} \mathrm{HA} / \mathrm{cm}^{3}\right)$ & $113.3 \pm 30.3$ & $111.9 \pm 32.0$ \\
\hline $\operatorname{TbN}\left(\mathrm{mm}^{-1}\right)$ & $1.36 \pm 0.33$ & $1.25 \pm 0.29$ \\
\hline $\operatorname{TbSp}(\mu \mathrm{m})$ & $680 \pm 268$ & $714 \pm 190$ \\
\hline $\operatorname{TbTh}(\mu \mathrm{m})$ & $68 \pm 15$ & $73 \pm 17$ \\
\hline Tb.1/N.SD & $0.41 \pm 0.34$ & $0.42 \pm 0 \cdot 23$ \\
\hline $\mathrm{CSA}_{\text {total }}\left(\mathrm{mm}^{2}\right)$ & $679 \pm 106$ & $627 \pm 115$ \\
\hline $\mathrm{CSA}_{\text {cort }}\left(\mathrm{mm}^{2}\right)$ & $74.4 \pm 2.2$ & $74.0 \pm 21.2$ \\
\hline $\mathrm{CSA}_{\text {trab }}\left(\mathrm{mm}^{2}\right)$ & $594 \pm 111$ & $542 \pm 123$ \\
\hline
\end{tabular}

Values are mean $\pm \mathrm{SD}$

$B M I$ body mass index; $B M D$ bone mineral density; $B V / T V$ bone volume fraction; CSA cross-sectional area (total, trabecular, or cortical); $C T h$ cortical thickness; $D$ bone density (trabecular or cortical); $T b N$ trabecular number; $T b S p$ trabecular separation; $T b T h$ trabecular thickness; Tb.1/N.SD heterogeneity of the trabecular network

alendronate $(0.5 \pm 2.0 \%, P=0.114) . \mathrm{D}_{\text {cort }}$ was $758.9 \pm$ $86.0 \mathrm{mg} \mathrm{HA} / \mathrm{cm}^{3}$ with strontium ranelate and $749.6 \pm$ $78.0 \mathrm{mg} \mathrm{HA} / \mathrm{cm}^{3}$ with alendronate (Table 2). CTh increased by $5.3 \pm 0.2 \%$ in the strontium ranelate group $(P<0.001)$ but was unchanged in the alendronate group $(1.3 \pm 6.0 \%, P=0.13)$. The between-group difference in favor of strontium ranelate was $3.9 \pm 1.9 \%(P=0.045)$. The increase in $\mathrm{CTh}$ with strontium ranelate was $2.9 \pm 4.9 \%$ at 3 months versus baseline $(P<0.001)$ and was $2.3 \pm 0.9 \%(P=0.012)$ greater than in the alendronate group (Fig. 1). The increase in CTh was associated with a significant increase in cortical area by $4.9 \pm 9.8 \%$ over 12 months (from $74.4 \pm 22.1$ to $77.4 \pm 21.8 \mathrm{~mm}^{2}$, $P=0.013$ ) and by $2.9 \pm 4.8 \%$ over 3 months (from $74.4 \pm$ 22.1 to $\left.75.9 \pm 21.7 \mathrm{~mm}^{2}, \quad P<0.001\right)$. No significant changes in cortical area were observed in the alendronate group over 1 year $(1.1 \pm 5.6 \%, 74.0 \pm 21.2$ to $74.8 \pm$ $\left.21.6 \mathrm{~mm}^{2}, P=0.178\right)$. The estimated between-group difference $(\mathrm{SE})$ was $1.1 \pm 0.4 \%(P=0.009)$ at 3 months and $3.8 \pm 1.8 \%(P=0.041)$ at 1 year. 
Table 2 Relative change (\%) from baseline to end of microstructure parameters at the distal tibia

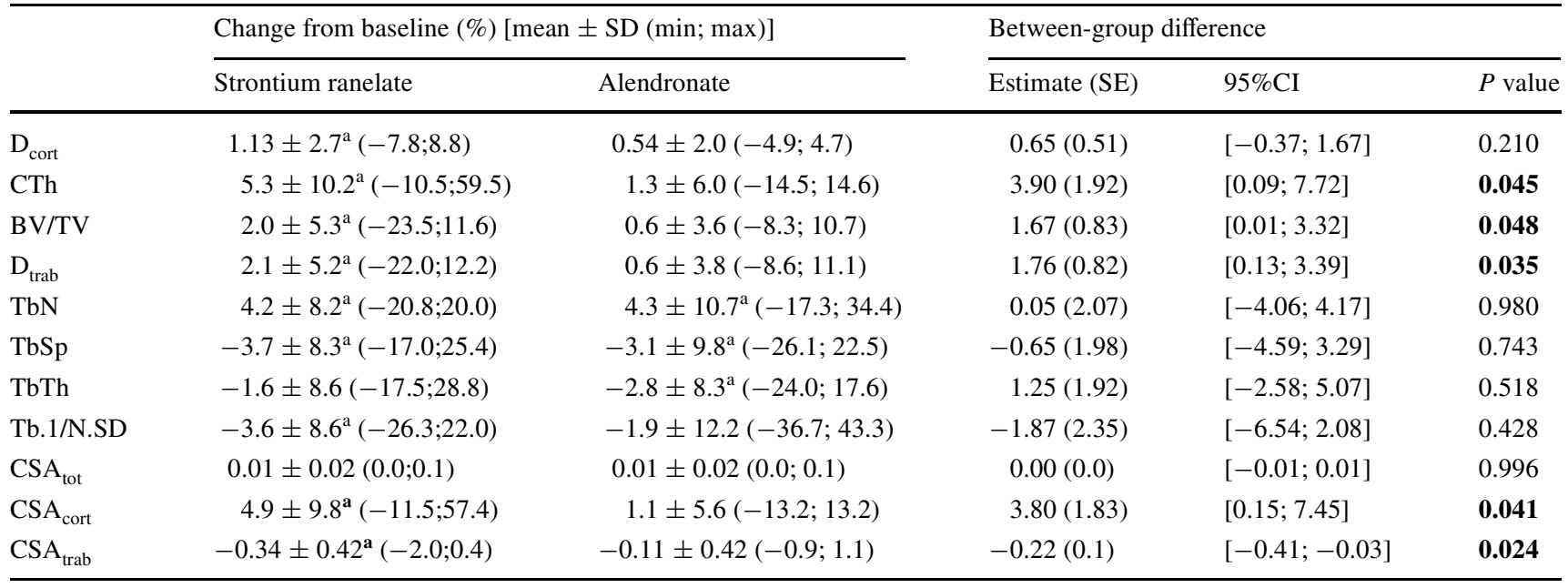

$P$ values $<0.05$ (significant) are in bold

$S E$ standard error; $C I$ confidence interval; $B V / T V$ bone volume fraction; $C S A$ cross-sectional area (total, trabecular, or cortical); $C T h$ cortical thickness; $D$ bone density (trabecular or cortical); $T b N$ trabecular number; $T b S p$ trabecular separation; TbTh trabecular thickness; Tb.1/N.SD heterogeneity of the trabecular network

${ }^{a} P<0.05$ versus baseline

Fig. 1 Change in cortical thickness $(\mathrm{CTh})(\mathbf{a})$ and relative trabecular bone volume (BV/TV) (b) over time (mean \pm sem) in the strontium ranelate and alendronate groups

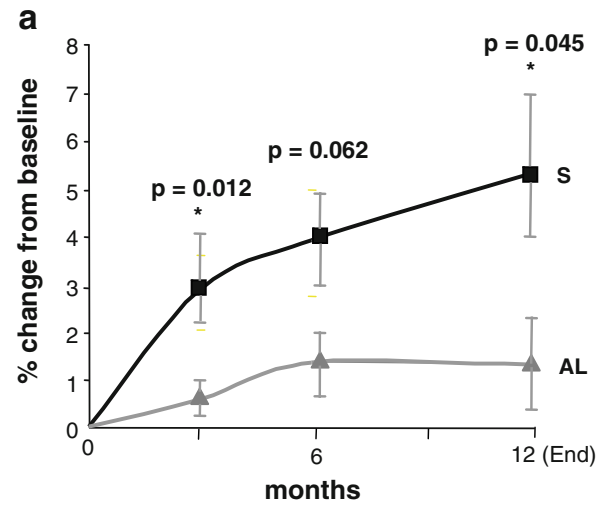

Strontium ranelate $2 \mathrm{~g} / \mathrm{day}$

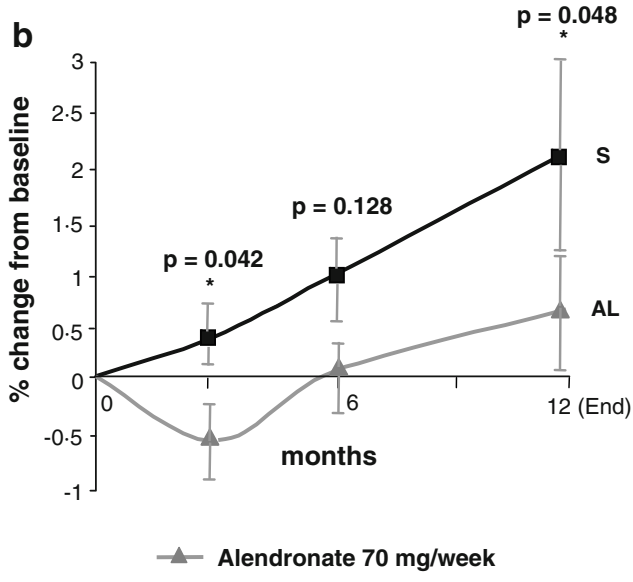

Distal tibia trabecular BV/TV increased by $2.0 \pm 5.3 \%$ and $\mathrm{D}_{\text {trab }}$ by $2.1 \pm 5.2 \%$ (both $P=0.002$ ) in the strontium ranelate group (Fig. 1). These changes were significant from 6 months (BV/TV, $0.9 \pm 2.3 \%, P=0.031 ; \mathrm{D}_{\text {trab }}$, $0.9 \pm 2.2 \%, P=0.033)$. No significant changes were observed in the alendronate group. The estimated betweengroup differences were $1.7 \pm 0.8 \%(P=0.048)$ for $\mathrm{BV} / \mathrm{TV}$ and $1.8 \pm 0.8 \%(P=0.035)$ for $\mathrm{D}_{\text {Trab }}$. TbN increased in the strontium ranelate and alendronate groups, $(4.2 \pm 8.2 \%$, $P=0.011$, and $4.3 \pm 10.7 \%, P=0.030$, respectively) with a corresponding decrease in trabeculae spacing (TbSp; $-3.7 \pm 8.3 \%, P=0.001$, and $-3.1 \pm 9.8 \%, P=0.031$ ) with no significant between-group differences. TbTh remained unchanged with strontium ranelate $(-1.6 \pm$ $8.6 \%, P=0.096)$ but decreased with alendronate $(-2.8 \pm$ $8.3 \%, P=0.024)$, and this was significant from 3 months $(-3.4 \pm 7.5 \%, P=0.007)$. The heterogeneity of the trabec- ular network decreased with strontium ranelate $(-3.6 \pm 8.6 \%, P=0.007)$, significantly from 6 months $(-3.2 \pm 8.1 \%, P<0.017)$ but remained unchanged with alendronate $(-1.9 \pm 12.2, \quad P=0.361)$. There was no between-group difference. Trabecular area decreased at 12 months in the strontium ranelate group $(-0.34 \pm$ $0.42 \%$, from 594 to $592 \mathrm{~mm}^{2}, P<0.001$ ) but not in the alendronate group $\left(-0.11 \pm 0.42 \%\right.$, from 542 to $541 \mathrm{~mm}^{2}$, $P=0.097)$. The estimated between-group difference was $-0.22 \pm 0.10 \%(P=0.024)$. Similar results were found at 3 months.

Out of 88 patients, only $63(72 \%)$ had assessable distal radius examinations, mainly due to movement artifacts. Of these patients, the relative changes in structural parameters evaluated by HR-pQCT was $\leq 1 \%$ for strontium ranelate and alendronate, respectively (mean relative change at M12 in CTh: $+0.3 \pm 6.2 \%$ and $-1.1 \pm 5.8 \%$; $\mathrm{D}_{\text {cort }}: 0.9 \pm 2.1 \%$ 
Table 3 Relative change in areal bone mineral density (aBMD) from baseline to end (mean $\pm \mathrm{SD}$ )

$S E$ standard error; $C I$ confidence interval

${ }^{a} P<0.001$ versus baseline

Fig. 2 Change from baseline over time (median, Q1 and Q3) of b-ALP (a) and S-CTX (b) in the strontium ranelate and alendronate groups

\begin{tabular}{|c|c|c|c|c|}
\hline & \multicolumn{2}{|c|}{ Change in aBMD $\left(\mathrm{g} / \mathrm{cm}^{2}\right)$} & \multicolumn{2}{|c|}{ Between-group difference } \\
\hline & $\begin{array}{l}\text { Strontium } \\
\text { ranelate }\end{array}$ & Alendronate & $\begin{array}{l}\text { Estimate } \\
\text { (SE) }\end{array}$ & $95 \% \mathrm{CI}$ \\
\hline Lumbar & $5.7 \pm 4.4^{\mathrm{a}}$ & $5.1 \pm 4.7^{\mathrm{a}}$ & $0.4(1.0)$ & {$[-1.64 ; 2.47]$} \\
\hline Femoral neck & $3.6 \pm 4.1^{\mathrm{a}}$ & $2.8 \pm 3.4^{\mathrm{a}}$ & $0.8(0.8)$ & {$[-0.91 ; 2.47]$} \\
\hline Total hip & $3.3 \pm 3.6^{\mathrm{a}}$ & $2.2 \pm 2.8^{\mathrm{a}}$ & $1.0(0.7)$ & {$[-0.47 ; 2.41]$} \\
\hline
\end{tabular}
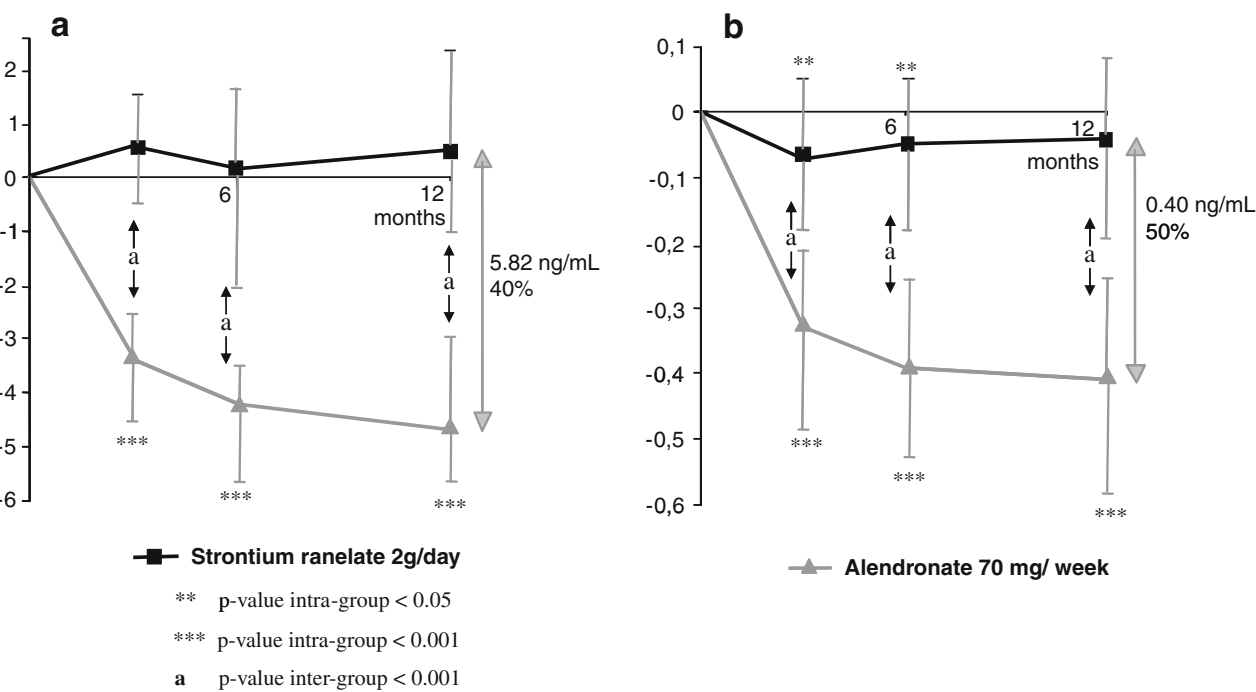

- Alendronate $70 \mathrm{mg} /$ week and $-0.2 \pm 1.7 \% ; \mathrm{BV} / \mathrm{TV}:-0.4 \pm 3.7 \%$ and $-0.3 \pm$ $4.4 \% ; \mathrm{D}_{\text {trab }}:-0.4 \pm 3.6 \%$ and $-0.6 \pm 4.2 \%$; TbN: $-0.1 \pm$ $5.9 \%$ and $-0.1 \pm 5.3 \%$; TbTh: $0.1 \pm 6.7 \%$ and $-0.3 \pm 6.1 \%$; TbSp: $0.4 \pm 6.1 \%$ and $0.3 \pm 5.6 \%$ CSA $_{\text {tot }}: 0.0 \pm 0.2 \%$ and $0.1 \pm 0.2 ; \mathrm{CSA}_{\text {cort }}: 0.4 \pm 5.7 \%$ and $-0.8 \pm 6.0 \% ; \mathrm{CSA}_{\text {trab }}$ : $0.2 \pm 1.0 \%$ and $-0.4 \pm 0.9 \%)$. A slight increase in cortical density was significant in the strontium ranelate group $(P=0.015)$ but not in the alendronate group $(P=0.577)$. The estimated between-group difference was $0.95 \pm 0.47 \%$ $(P=0.05)$. There were no other significant within- or between-group differences (data not shown).

The mean bone strontium content from biopsies sampled in postmenopausal women after 3 years of treatment from the SOTI and TROPOS studies was $1.8 \%$, four times more than at 1 year. No correlation was detected between CTh and bone strontium content $\left(r^{2}=0.003, y=-30.03 x+\right.$ 816). Similarly, there was no correlation between distal tibia cortical thickness and area, and serum strontium levels $\left(r^{2}=0.235 ; P=0.134\right.$ and $r^{2}=0.241 ; P=0.124$ respectively).

Lumbar, total hip and femoral neck aBMD increased in both groups and did not differ between groups (Table 3). In the strontium ranelate group, b-ALP increased by a median of $0.55 \mathrm{ng} / \mathrm{mL}(+4.1 \%, P=0.095)$ at 3 months and $0.6 \mathrm{ng} / \mathrm{mL}$ $(+5 \%, P=0.082)$ at 12 months. S-CTX remained unchanged (median, $-0.04 \mathrm{ng} / \mathrm{mL},-7 \%, P=0.250$ ). In the alendronate group, both b-ALP and S-CTX decreased (median,
$-4.7 \mathrm{ng} / \mathrm{mL},-35 \%, P \leq 0.001$, and $-0.36 \mathrm{ng} / \mathrm{mL},-58 \%$, $P<0.001$, respectively). Between-group differences at 1 year were 40 and $55 \%$, respectively $(P \leq 0.001$ each $)$ (Fig. 2).

Adverse events were analyzed in pooled groups to maintain blinding. One patient withdrew because of development of a peptic ulcer and one for upper abdominal pain. Both events were considered as related to the study drug by the investigator. Four patients suffered a rash, three were considered as possibly or doubtfully related to the study drug; all were mild, one led to treatment withdrawal. Two patients had an increase in CPK judged clinically significant by the investigator, one case at 6 months that spontaneously recovered on treatment and one case at 12 months. Both values were lower than three times the upper limit of the normal range.

\section{Discussion}

To our knowledge, this is the first head-to-head, doubleblind, randomized controlled trial comparing effects of strontium ranelate and alendronate on bone microstructure. Strontium ranelate increased cortical thickness, cortical area and trabecular density after 1 year of treatment. Trabecular bone volume and density increased with a decrease in the heterogeneity of the trabecular network. No change 
was observed with alendronate. The increases in cortical thickness, cortical area, and BV/TV and decrease in trabecular bone area were greater in the strontium ranelate than in the alendronate group. Trabecular number increased in both groups.

While these results suggest that strontium ranelate has a positive effect on bone microstructure, they require cautious interpretation given changes in tissue mineralization may modify the attenuation characteristics of photons during HR-pQCT imaging [26]. Both drugs might artifactually increase edge detection. Strontium ranelate has twice the atomic number of calcium and alendronate increases the mean degree of mineralization [27]. Cortical thickening suggests that there is an increase in periosteal and/or endocortical bone formation but neither can be confirmed as endocortical perimeter was not available with the HRpQCT technique used in this study, while periosteal perimeter (a measure of periosteal apposition) and total crosssectional area are used to match the volumes of interest between baseline and postbaseline exams. Moreover, cortical area may increase without change in periosteal or endocortical perimeters if there is filling of intracortical pores with mineralized bone. This will also result in an apparent increase in the cortical thickness given it is calculated as cortical area/perimeter [28].

While these possibilities cannot be excluded, bone strontium content is low after 1 year $(0.43 \pm 0.28 \%, n=8)$ [25]. After 3 years treatment, with a strontium content of $1.8 \%$, four times more than at 1 year, strontium is present in only $37 \%$ of the bone surface and mainly trabecular surfaces [25]. Furthermore, after 3 months of treatment, when bone strontium content is plausibly lower $(2.2 \%$ of the bone area with strontium and $0.14 \%$ of strontium in bone) [25], increases in cortical thickness, cortical area and BV/TV are already observed in the strontium ranelate group, making less likely that the changes observed are entirely due to the higher atomic number of strontium and issues concerning edge detection. Furthermore, we did not detect any positive correlation between cortical thickness and area, and serum strontium levels.

We also performed a simulation to quantify the possible influence of strontium content on X-ray linear attenuation in the evaluation of CTh (A. Laib, Scanco Medical AG, personal communication). Calculations were based on the results of Boivin and colleagues [25] who quantified, in bone biopsies of patients treated for 2 or 3 years with strontium ranelate $2 \mathrm{~g} / \mathrm{day}$, the strontium content in cortical bone (newly formed and "old" bone) and the percentage of bone area containing strontium. We also used the linear attenuation coefficients $(\mathrm{mu} / \mathrm{rho})$ of cortical bone, of calcium and of strontium given by the National Institute of Standards and Technology (http://physics.nist.gov/PhysRefData/Xray MassCoef/cover.html). We calculated the percentage of strontium after 1 year of treatment in the cortical bone and estimated the variation of X-ray linear attenuation due to the replacement of calcium atoms by this quantity of strontium atoms. This led to an increase in linear attenuation coefficient of $0.255 \%$.

Then, we electronically changed the pixel values of the cortex pixels to increase them by the estimated $0.255 \%$, and processed the scans again. The resulting CTh was $0.49 \%$ higher than the initially measured CTh.

This means that a small part of the increase in cortical thickness in strontium ranelate group could be related to strontium dependent overestimation of the measurement.

Trabecular volumetric BMD increased in the strontium ranelate group due to an increase in trabecular number not thickness. This was associated with a corresponding decrease in trabecular spacing and an improvement of the trabecular homogeneity consistent with improved trabecular architecture. These observations may also be the result of changes in attenuation characteristics. Trabeculae that were not detectable at baseline may have become detectable due to an increase in edge detection. This possibility would also account for the increase in $\mathrm{TbN}$ in the alendronate group without a change in BV/TV as alendronate increases secondary mineralization (even though no increase in tissue density was detected at 1 year) by suppressing remodeling $[11,13]$. This could also explain the apparent decrease observed in trabecular thickness since this parameter is derived from $\mathrm{TbN}$.

The groups were similar in terms of baseline characteristics, including HR-pQCT parameters. The increases in aBMD in the two groups were similar to those previously observed [21-23]. The results on bone markers are also in accordance with published data. The changes in b-ALP with strontium ranelate were of a similar magnitude to those observed in the SOTI study [21]. The lack of significance in the present study may be due to a small sample size and a great inter-patient variation for the change from baseline to end. In the alendronate group, the decrease in SCTX by roughly $60 \%$ preceded the decrease in b-ALP, as demonstrated elsewhere [29].

Within the constraints imposed by methodological issues described earlier, with strontium possibly influencing X-ray attenuation, we infer that strontium ranelate improved bone microstructure within 3 months, while alendronate preserves existing structures. The observed changes in structure and density using strontium ranelate require confirmation with larger sample sizes and using dynamic histomorphometry.

Acknowledgments The study was sponsored by Servier.

Conflict of interest statement All authors are investigators in the study. 
Open Access This article is distributed under the terms of the Creative Commons Attribution Noncommercial License which permits any noncommercial use, distribution, and reproduction in any medium, provided the original author(s) and source are credited.

\section{References}

1. Parfitt A, Mathews CH, Villanueva AR, Kleerekoper M, Frame B, Rao DS (1983) Relationships between surface, volume and thickness of iliac trabecular bone in aging and in osteoporosis. Implications for the microanatomic and cellular mechanisms of bone loss. J Clin Invest 72:1396-1409

2. Seeman E, Delmas PD (2006) Bone quality-the material and structural basis of bone strength and fragility. N Engl J Med 354(21):2250-2261

3. Delmas PD (2002) Treatment of postmenopausal osteoporosis. Lancet 359(9322):2018-2026

4. Boutroy S, Bouxsein M, Munoz F, Delmas P (2005) In vivo assessment of trabecular bone microarchitecture by high resolution peripheral quantitative computed tomography. J Clin Endocrinol Metab 90:6508-6515

5. Laib A, Hildebrand T, Haüselmann HJ, Rüegsegger P (1997) Ridge number density: a new parameter for in vivo bone structure analysis. Bone 21(6):541-546

6. Laib A, Rüegsegger P (1999) Calibration of trabecular bone structure measurements of in vivo three-dimensional peripheral quantitative computed tomography with 28-microm-resolution microcomputed tomography. Bone 24(1):35-39

7. Seeman E (2007) Is a change in bone mineral density a sensitive and specific surrogate of anti-fracture efficacy? Bone 41(3):308317

8. Liberman UA, Weiss SR, Bröll J et al (1995) Effect of oral alendronate on bone mineral density and the incidence of fractures in postmenopausal osteoporosis, The Alendronate Phase III Osteoporosis Treatment Study Group. N Engl J Med 333(22):14371443

9. Papapoulos SE (2008) Bisphosphonates: how do they work? Best Pract Res Clin Endocrinal Metab 22(5):831-847

10. Russel RG, Watts N, Ebetino F, Rogers M (2008) Mechanisms of action of bisphosphonates: similarities and differences and their potential influence on clinical efficacy. Osteoporos Int 19:733-759

11. Chavassieux PM, Arlot ME, Reda C, Wei L, Yates J, Meunier PJ (1997) Histomorphometric assessment of the long-term effects of alendronate on bone quality and remodelling in patients with osteoporosis. J Clin Invest 100:1475-1480

12. Arlot M, Meunier PJ, Boivin G et al (2005) Differential effects of teriparatide and alendronate on bone remodeling in postmenopausal women assessed by histomorphometric parameters. J Bone Miner Res 20:1244-1253

13. Recker R, Masarachia P, Santora AC et al (2005) Trabecular bone microarchitecture after alendronate treatment of osteoporotic women. Curr Med Res Opin 21:185-194

14. Balena R, Toolan BC, Shea M, Markatos A, Myers ER, Lee SC, Opas EE, Seedor JG, Klein H, Frankenfield D et al (1993) The effects of 2-year treatment with the aminobisphosphonate alendro- nate on bone metabolism, bone histomorphometry, and bone strength in ovariectomized nonhuman primates. J Clin Invest 92(6):2577-2586

15. Arlot M, Jiang Y, Genant $\mathrm{H}$ et al (2008) Histomorphometric and microCT analysis of bone biopsies from postmenopausal osteoporotic women treated with strontium ranelate. J Bone Miner Res 23(2):215-222

16. Brennan TC, Rybchyn MS, Green W, Atwa S, Conigrave AD, Mason RS (2009) Osteoblasts play key roles in the mechanisms of action of strontium ranelate. Brit L Pharmacol 157(7):1291-1300

17. Bonnelye E, Chabadel A, Saltel F, Jurdic P (2008) Dual Effect of strontium ranelate: stimulation of osteoblast differentiation and inhibition of osteoclast formation and resorption in vitro. Bone 42:129-138

18. Chattopadhyay N, Quinn SJ, Kifor O, Ye C, Brown EM (2007) The calcium-sensing receptor $(\mathrm{CaR})$ is involved in strontium ranelate-induced osteoblast proliferation. Biochem Pharmacol 74(3):438-447

19. Atkins GJ, Welldon KJ, Halbout P, Findlay DM (2009) Strontium ranelate treatment of human primary osteoblasts promotes an osteocyte-like phenotype while eliciting an osteoprotegerin response. Osteoporos Int 20:653-664

20. Bain SD, Jerome C, Shen V, Dupin-Roger I, Ammann P (2009) Strontium ranelate improves bone strength in ovariectomized rat by positively influencing bone resistance determinants. Osteoporos Int 20(8):1417-1428

21. Meunier PJ, Roux C, Seeman E et al (2004) The effects of strontium ranelate on the risk of vertebral fracture in women with postmenopausal osteoporosis. N Engl J Med 350(5):459-468

22. Reginster JY, Seeman E, De Vernejoul C et al (2005) Strontium ranelate reduces the risk of nonvertebral fractures in postmenopausal women with osteoporosis: treatment of peripheral osteoporosis (TROPOS) study. J Clin Endocrinol Metab 90(5):2816-2822

23. Black D, Cummings S, Karpf D et al (1996) Randomised trial of effects of alendronate on risk of fracture in women with existing vertebral fractures. Lancet 348:1535-1541

24. Laib A, Hauselmann HJ, Ruegsegger P (1998) In vivo resolution 3D-QCT of the human forearm. Thechnol Health Care 6:329-337

25. Boivin G, Farlay D, Khebbab MT, Jaurand X, Delmas PD, Meunier PJ (2009) In osteoporotic women treated with strontium ranelate, strontium is located in bone formed during treatment with a maintained degree of mineralization. Osteoporos Int 2010 Apr; 21(4):667-677

26. Boivin G, Meunier PJ (2003) The mineralization of bone tissue: a forgotten dimension in osteoporosis research. Osteoporos Int 14(Suppl 3):S19-S24

27. Boivin G, Chavassieux P, Santora AC (2000) Alendronate increases bone strength by increasing the mean degree of mineralization of bone tissue in osteoporotic women. Bone 27:687-694

28. Davis KA, Burghardt AJ, Link TM, Majumdar S (2007) The effects of geometric and threshold definitions on cortical bone metrics assessed by in vivo high-resolution peripheral quantitative computed tomography. Calcif Tissue Int 81:364-371

29. Garnero P, Shih W, Gineyts E, Karpf D, Delmas P (1994) Comparison of new biochemical markers of bone turnover in late postmenopausal osteoporotic women in response to alendronate treatment. J Clin Endocrinol Metab 79(6):1693-1700 